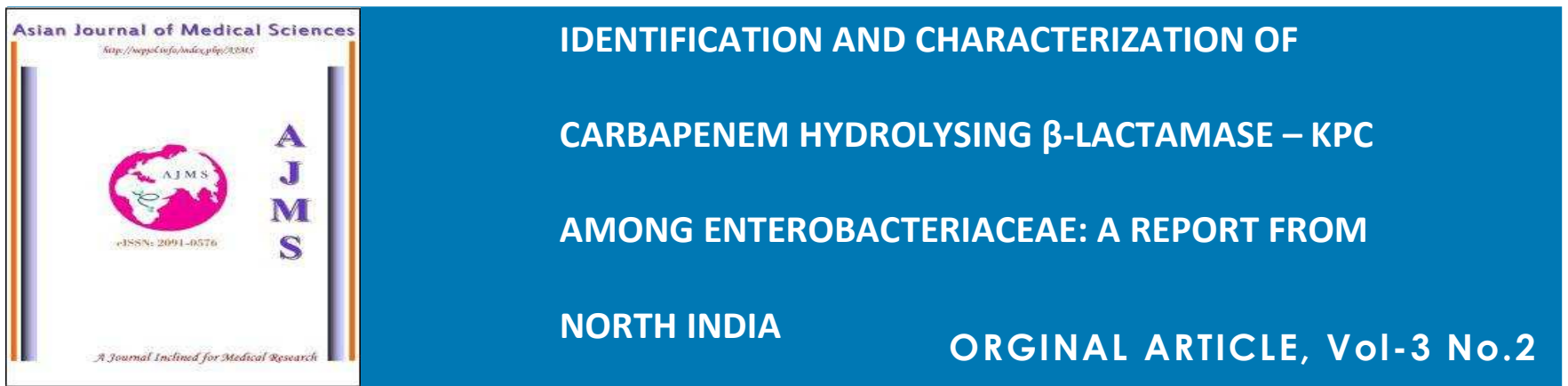

Asian Journal of Medical Science, Volume-3(2012)

http://nepjol.info/index.php/AJMS

Supriya Upadhyay ${ }^{1}$, Malay Ranjan Sen ${ }^{1}$, Amitabha Bhattacharjee ${ }^{2}$ 1.Department of Microbiology, Institute of Medical Sciences, Banaras Hindu University, Varanasi - 221005, India. 2. Department of Microbiology, Assam University, Silchar-788011, India

\title{
ABSTRACT
}

\section{CORRESPON DENCE:}

Prof. Malay Ranjan Sen Department of Microbiology Institute of Medical Sciences, Banaras Hindu University, Varanasi-221005, India Telephone: +919415820675 Fax: +915422367568 Email

ID:mr_senbhu@yahoo.com

"With the current scenario of wide dissemination of NDM in the Indian subcontinent, the identification and rapid spread of KPC have raised concerns, due to their high transmissibility and epidemic potential"

\section{Objective:}

The serine carbapenemase KPC (Klebsiella pneumoniae carbapenemase) has emerged as a beta-lactamase capable of inactivating carbapenem antibiotics. The emergence of carbapenem-resistant enterobacteria is therefore worrisome, since consequently the antimicrobial treatment options are very restricted. In the present study we have reported the presence of KPC $\beta$ lactamase producing enterobacterial isolates from a tertiary referral hospital in north India.

\section{Methods:}

The isolates were subjected to phenotypic confirmatory test by boronic acid and clavulanic acid inhibition and presence of carbapenemase activity. They were further tested for PCR detection of $b / a_{\mathrm{KPC}}$ and the associated genetic component.

\section{Results:}

Three enterobacterial isolates were found to be phenotypically similar to that of KPC enzyme and genotypically showing positive results with primers specific for bla $a_{\mathrm{KPC}}$ gene were found to be located on integron.

\section{Conclusion:}

The findings indicate the need for continuous surveillance of this resistant determinant in this part of the world.

Key Words: Serine Carbapenemases, KPC, Integron 


\section{INTRODUCTION}

Carbapenem remains the most appropriate treatment option for extended spectrum beta lactamase (ESBL) and AmpC beta-lactamase producing organisms. The emergence of carbapenem-resistant enterobacteria is therefore worrisome, since consequently the antimicrobial treatment options are very restricted. Klebsiella pneumoniae carbapenemases (KPCs) are one of the most frequently reported Ambler's class A carbapenemases and are generally plasmidencoded enzymes. KPC enzymes have the ability to hydrolyze $\beta$-lactams of all classes including the carbapenems. Hydrolysis capacity is high for penicillins and first generation cephalosporins while it is low for carbapenems, oxyiminocephalosporins, monobactam and cephamycins. ${ }^{1}$ The first member of KPC family, KPC-1 was discovered in 1996 from North Carolina. ${ }^{2}$ Soon after its expansion in United States, particularly in New York, hospital outbreaks of infection caused by KPC-producing isolates in Israel were reported. KPC producers are also an emerging public health concern in Europe, China and Central and South America. ${ }^{3}$ Although predominant in Klebsiella pneumoniae, they have also been discovered in other species from Enterobacteriaceae family and there is recent report of plasmid mediated KPC from Pseudomonas aeruginos ${ }^{1}$ and Acinetobacter baumannii ${ }^{4}$.

Detection of these KPC producers remains difficult, and cannot rely on results of antibiotic susceptibility testing. Most worrisome is the treatment of infections caused by these organisms due to heterogeneous expression of these multidrug resistant organisms that result in long hospital stay and high mortality rates. ${ }^{1}$ Here, in the present study we have reported the presence of KPC $\beta$-lactamase producing enterobacterial isolates from a tertiary referral hospital in north India.

\section{MATERIALS AND METHODS}

Three enterobacterial isolates Kp 58, Ec 445 and Ec 449, were obtained from patients admitted in a tertiary referral hospital of north India. The first isolate was Klebsiella pneumoniae (Kp 58), isolated from a blood culture of an 18 years old male from intensive care unit (ICU) in July 2008. The second isolate was Escherichia coli (Ec 445), isolated from a urine specimen of a 60 years old male treated for pyelonephritis, the nephrology ward in March 2009. The third one was E. coli (Ec 449), isolated two days later from a urine sample of a 3 year old male admitted to pediatric ward in March 2009. Written informed consent was obtained from the patient(s) for publication of this manuscript and accompanying images. This work has been ethically approved by the chairperson of the ethical committee of Institute of Medical Sciences.

All the three isolates showed Minimum inhibitory concentration $\geq 2 \mu \mathrm{g} / \mathrm{ml}$ against ertapenem and were tested for boronic acid ${ }^{5}$ and clavulanic acid inhibition. ${ }^{6}$ They were further tested for carbapenemase activity by modified Hodge test. ${ }^{7}$ A previously confirmed carbapenemase producing E. coli was taken as positive control for Hodge test.

Isolates were also subjected to detection of AmpC $\beta$-lactamase activity by modified three dimensional testing, ${ }^{8}$ ESBL detection by combined disc diffusion method according to CLSI recommendation $^{6}$ and metallo $\beta$-lactamase production by imipenem-EDTA disc test. ${ }^{6}$

Isolates were subjected to polymerase chain reaction (PCR) detection of $b / a_{\mathrm{KPC}}$ using primers described previously. ${ }^{9}$ The reaction mixture (total volume $25 \mu \mathrm{l}$ ) contained $5 \mu \mathrm{l}$ of template, $15 \mathrm{pmol}$ (each) primers, 10mM dNTPs, 10X reaction buffer and $1 \mathrm{U}$ Taq polymerase (Genei, Bangalore, India). The reaction condition was initial denaturation of $95^{\circ} \mathrm{C}$ for $5 \mathrm{~min}$ followed by 35 cycles of 
denaturation at $95^{\circ} \mathrm{C}$ for $1 \mathrm{~min}$, annealing at $56^{\circ} \mathrm{C}$ for $30 \mathrm{~s}$ and extension at $72^{\circ} \mathrm{C}$ for $1 \mathrm{~min} 30 \mathrm{~s}$. The amplification was ended by a final extension cycle at $72^{\circ} \mathrm{C}$ for $1 \mathrm{~min}$. The reactions were amplified in $\mathrm{MJ}$ Mini Thermal cycler (Bio-Rad, USA). The amplicons were sequenced and compared by performing BLAST (http://blast.ncbi.nlm.nih.gov/Blast.cgi). Negative controls used in the PCR reaction were $E$. coli ATCC 25922, three previously confirmed isolates of $E$. coli producing $b / a_{\mathrm{CTX}-\mathrm{M}}, b / a_{\mathrm{CIT}}$ and $b / a_{\mathrm{NDM}-1}$.

For PCR detection of ESBL ${ }^{10}$ and AmpC $\beta$-lactamase ${ }^{11}$ genes, multiplex PCR was performed. PCR conditions and primers were as described previously. ${ }^{10,11}$

Presence of integron was detected by integrase gene PCR. ${ }^{12}$ To find their genetic association with bla $_{\mathrm{KPC}}, 5^{\prime}$-CS GGC ATC CAA GCA GCA AG primers ${ }^{12}$ and reverse primers of bla $a_{\mathrm{KPC}}$ was used in the PCR reaction.

Antimicrobial Susceptibility testing was performed by disc diffusion method against cefuroxime $(30 \mu \mathrm{g})$, cefoxitin (30 $\mathrm{g})$, co-trimoxazole $(25 \mu \mathrm{g})$, ciprofloxacin $\quad(5 \mu \mathrm{g})$, piperacillin/tazobactam $(100 / 10 \mu g)$, netilmicin $(30 \mu \mathrm{g})$, gentamicin $(10 \mu \mathrm{g})$, kanamycin $(10 \mu \mathrm{g})$, tigecycline $(15 \mu \mathrm{g})$ and polymixin B $(300 \mu \mathrm{g})$ (Hi-Media, Mumbai, India). The results were interpreted according to the CLSI guidelines. ${ }^{6}$ MIC was determined by agar dilution method against cefotaxime, ceftazidime, ceftriaxone, cefepime, aztreonam (Aristo Pharmaceuticals Ltd., Mumbai, India), imipenem (United Biotech, Solan, India), meropenem (Astra Zeneca Pharmaceuticals Ltd., Bangalore, India) and ertapenem (Invanz, Bhiwandi, India). Tests were performed and interpreted according to CLSI guidelines. ${ }^{8}$

Strains were typed by random amplification of polymorphic DNA (RAPD) using primer $7 .{ }^{13}$ The reaction conditions were as described previously. ${ }^{13}$

\section{RESULTS}

The three isolates showed inhibition by both clavulanic acid and boronic acid. The carbapenemase activity was confirmed by modified hodge test. All of them were negative by imipenemEDTA disc test for the presence of metallo $\beta$ lactamases. MIC study showed the isolates were resistant to cephalosporins while false susceptibility was observed against imipenem and meropenem (Table 1).

Table 1: MIC $(\mu \mathrm{g} / \mathrm{ml})$ of KPC positive isolates against different beta-lactam drugs

\begin{tabular}{|c|c|c|c|c|c|}
\hline Antibiotics & Kp 58 & Ec 445 & Ec 449 & $\begin{array}{l}\text { E. coli } \\
25922 \\
\text {-ve } \\
\text { control }\end{array}$ & $\begin{array}{c}\text { NDM } \\
\text { +ve } \\
\text { isolate }\end{array}$ \\
\hline Cefotaxime & $\geq 1024$ & $\geq 1024$ & 64 & $\leq 2$ & $\geq 1024$ \\
\hline Ceftazidime & $\geq 1024$ & $\geq 1024$ & 64 & $\leq 2$ & $\geq 1024$ \\
\hline Ceftriaxone & $\geq 1024$ & $\geq 1024$ & 128 & $\leq 2$ & $\geq 1024$ \\
\hline Cefepime & $\geq 1024$ & $\geq 1024$ & 32 & $\leq 2$ & $\geq 1024$ \\
\hline Aztreonam & $\geq 1024$ & $\geq 1024$ & 32 & $\leq 2$ & $\geq 1024$ \\
\hline Imipenem & 2 & 2 & 0.25 & $\leq 0.125$ & $\geq 16$ \\
\hline
\end{tabular}

On disc diffusion testing they were susceptible only against tigecyclin and polymixin. On performing PCR amplification with $b / a_{\mathrm{KPC}}$ primers was found in all of them. The reaction was repeated four times which yielded the same result in each occasion. None of the control strains showed any amplification in the PCR reaction. Multiplex PCR for $b / a_{\mathrm{AmpC}}$ and $b / a_{\mathrm{ESBL}}$ did not show any amplification for the KPC positive strains. Sequencing of $b / a_{\mathrm{KPC}}$ PCR product showed 99 to $100 \%$ similarities among three of them by BLAST search. All the three isolates were harbouring class I integron. Association of integron and $b / a_{\mathrm{KPC}}$ was established as two of the $E$. coli isolates showed an amplicon of $950 \mathrm{bp}$ in size when a forward primer from 5' conserved sequence of integron $\mathrm{I}$ and $b / a_{\mathrm{KPC}}$ reverse primer was used. On typing of the strains, RAPD showed the isolates were of different clonality. 


\section{DISCUSSION}

So far, in this continent KPC producing organisms has been detected in Israel ${ }^{14}$ and China. ${ }^{15}$ In India, carbapenemase mediated resistance in enterobacteriaceae is generally due to presence of metallo $\beta$-lactamase. ${ }^{16,17}$ However, two previous studies reported the presence of KPC $\beta$-lactamase which included one from north and the other from southern part of this country. ${ }^{18,19}$ But no genotypic characterization was done for the earlier reported isolates. While observing the genetic environment of $b / a_{\mathrm{KPC}}$ gene, their location in class I integron is well established. The strains in this study were isolated from patients housed in different locations within the hospital and were non-clonal as evident from RAPD experiment, underlines the horizontal transmission of the drug resistant determinants in hospital environment which was also reflected in the heterogenous nature of the strains examined.

In this study, none of the isolates were found to be in-vitro resistant to imipenem and meropenem by routine disc diffusion method. It shows the potential risk of interpreting the isolates as ESBLs in routine clinical microbiology laboratory.

\section{CONCLUSION}

In light of our current struggle with New Delhi Metallo $\beta$-lactamase (NDM-1) producing Enterobacteriaceae, the presence of another resistance mechanism would further augment its grave situation. Thus a coordinated approach by clinicians and microbiologists in hospital settings is required for their laboratory detection, continuous monitoring of their genetic environment and formulation of proper antimicrobial policy to prevent or at least slow down the horizontal transmission of this drug resistant determinant.

\section{ACKNOWLEDGEMENTS}

The authors acknowledge the support of Head, department of Microbiology, IMS, BHU, Varanasi, India. The authors would also like to acknowledge the financial assistance provided by the Department of Biotechnology (DBT Project P-07-467), Government of India.

Ethical Approval: This work has been ethically approved by the chairperson of the ethical committee of Institute of Medical Sciences.

Conflict of interest: No conflict of interest to declare.

\section{REFERENCES}

1. Queenan AM, Bush K. Carbapenemase: the versatile betalactamases. Clin Microbiol Rev 2007, 20: 440-58.

2. Yigit $H$, Queenan AM, Anderson GJ, Domench-Sanchez A, Biddle JW, Steward CD, Albert S, Bush K, Tenover FC. Novel carabapenem hydrolyzing beta-lactamase, KPC-1, from a carbapenem resistant strain of Klebsiella pneumoniae. Antimicrob Agents Chemother 2001, 45:1151-61.

3. Nordmann P, Cuzon G, Naas T. The real threat of Klebsiella pneumoniae carbapenemase-producing bacteria. Lancet Infect Dis 2009; 9: 228-36.

4. Robledo IE, Aquino EE, Sante MI et al. Detection of KPC in Acinetobacter sp. in Puerto Rico. Antimicrob Agents Chemother 2010; 54: 1354-7.

5. Tsakris A, Kristo I, Poulou A, et al. Evaluation of boronic acid disk tests for differentiating KPC-possessing Klebsiella pneumoniae isolates in the clinical laboratory. J Clin Microbiol 2009, 47:362-7

6. CLSI. Perfomance Standards for antimicrobial disc susceptibility tests. CLSI:Wayne PA; 2005. p. M100-S15

7. Lee K, Chong Y, Shin HB, Kim YA, Yong D, Yum JH. Modified Hodge test and EDTA-disk synergy tests to screen metallo$\beta$-lactamase producing strains of Pseudomonas and Acinetobacter species. Clin. Microbiol. Infect 2001, 7:8891.

8. Manchanda V, Singh NP. Occurrence and detection of AmpC $\beta$-lactamases among Gram negative clinical isolates using a modified three-dimensional test at Guru Tegh Bahadur Hospital, Delhi, India. J Antimicrob Chemother 2003, 51:415-8.

9. Woodford N, Zhang J, Warner M, Kaufmann ME, Matos J, MacDonald A, Brudney D, Sampolinsky D, Venezia S N, Livermore DM. Arrival of Klebsiella pneumoniae producing KPC carbapenemase in the United Kingdom. J Antimicrob Chemother 2008, 62: 1261-64.

10. Bhattacharjee A, Sen MR, Prakash P, Anupurba S. Role of $\beta$-lactamase inhibitors in enterobacterial isolates producing extended-spectrum $\beta$-lactamases. J Antimicrob Chemother 2008, 61:309-14.

11. Pe'rez-Pe'rez FJ, Hanson ND. Detection of plasmidmediated AmpC $\beta$-lactamase genes in clinical isolates by using multiplex PCR. J Clin Microbiol 2002, 40: 2153-2162.

12. Koeleman JGM, Stoof J, Van der bijl MW, Vandenbrouckegrauls CMJE, Savelkoul PHM. Identification of Epidemic 
Strains of Acinetobacter baumannii by Integrase Gene PCR. J Clin Microbiol 2001, 39:8-13

13. Belkum AV, Kluytmans J et al. Multicenter evaluation of arbitrarily primed PCR for typing of Staphylococcus aureus strains. J Clin Microbiol 1995, 33:1537-47.

14. Leavitt A, Carmeli Y, Chmelnitsky I, Goren MG, Ofek I, Venezia $\mathrm{SN}$. The molecular epidemiology of KPC-producing Klebsiella pneumoniae strains in Israel, sequence types and plasmid analyses. Antimicrob Agents Chemother 2010, doi:10.1128/AAC.01818-09.

15. Shen $P$, Wei Z, Jiang $Y$, Du X, Ji S, Yu Y, Li L. Novel genetic environment of the carbapenem-hydrolysing beta-lactamase KPC-2 among Enterobacteriaceae in China. Antimicrob Agents Chemother 2009, doi:10.1128/AAC.00260-09.

16. Kumarasamy KK, Toleman MA, Walsh TR, Bagaria J, Butt F, Balakrishnan R, Chaudhary U, Doumith M, Giske CG, Irfan S, Krishnan P, Kumar AV, Maharjan S, Mushtaq S, Noorie T, Paterson DL, Pearson A, Perry C, Pike R, Rao B, Ray U, Sarma JB, Sharma M, Sheridan E, Thirunarayan MA, Turton J, Upadhyay S, Warner M, Welfare W, Livermore DM, Woodford $\mathrm{N}$ : Emergence of a new antibiotic resistance mechanism in India, Pakistan, and the UK: a molecular, biological, and epidemiological study. Lan Infect Dis 2010, 10: 597-602.

17. Deshpande P, Rodrigues C, Shetty A, Kapadia F, Hedge A, Soman R. New Delhi Metallo- $\beta$ lactamase (NDM-1) in Enterobacteriaceae: treatment options with carbapenems compromised. J Assoc Physi Ind 2010, 58: 147-149.

18. Rizvi M, Fatima N, Rashid M, Shukla I, Malik A, Usman A, Siddiqui $S$. Extended spectrum AmpC and metallo-betalactamases in Serratia and Citrobacter spp. in a disc approximation assay. J Infect Dev Ctries 2009, 3: 285-294.

19. Parveen RM, Harish BN, Parija SC. Emerging carbapenem resistance among nosocomial isolates of Klebsiella pneumoniae in south India. Int J Pharma Bio Sciences 2010, 2: 1-11. 